\title{
Non-Steady-State Measurement of in vivo Receptor Binding with Positron Emission Tomography: "Dose-Response" Analysis
}

\author{
Joel S. Perlmutter, ${ }^{1,2}$ Michael R. Kilbourn, ${ }^{2, a}$ Michael J. Welch, ${ }^{2}$ and Marcus E. Raichle ${ }^{1,2,3}$ \\ 1 Department of Neurology and Neurological Surgery, ${ }^{2}$ Mallinckrodt Institute of Radiology, and ${ }^{3}$ McDonnell Center for \\ Studies of Higher Brain Function, Washington University School of Medicine, St. Louis, Missouri 63110
}

\begin{abstract}
We previously developed a non-steady-state technique using positron emission tomography (PET) and the radioligand ${ }^{18} \mathrm{~F}$-spiperone ( $\left.{ }^{18} \mathrm{~F}-\mathrm{SP}\right)$ for the measurement of in vivo radioligand-receptor binding in brain. The purpose of this investigation is to determine the sensitivity of this method to alterations in the apparent number of available specific binding sites. Nine studies were performed on the same baboon. The animal was pretreated with varying doses of unlabeled SP $(15-600 \mu g)$ to compete for specific binding sites. The experimental procedure included measurement of regional cerebral blood flow, cerebral blood volume, and the protein binding of ${ }^{10} \mathrm{~F}-\mathrm{SP}$ in arterial blood. At least $3.5 \mathrm{hr}$ after pretreatment, no-carrier-added ${ }^{18 F-S P}$ (containing $<3 \mu \mathrm{g} \mathrm{SP}$ ) was administered intravenously. Sequential PET scans and measurements of arterial-blood radioactivity due to radioligand and its labeled metabolites continued for $3 \mathrm{hr}$. A 3-compartment model representing the in vivo behavior of radioligand was used to analyze the data. As expected, we found that an index of binding called the combined forward rate constant (which equals the product of the apparent maximum number of available specific binding sites and the association rate constant of radioligand for receptor) declined with increasing dose of unlabeled SP. Other estimated variables including the dissociation rate constant did not change. This demonstrates that our non-steady-state method for estimating radioligand-receptor binding kinetics can detect a decrease in the apparent number of available specific binding sites. This is an important step in the validation of this in vivo receptor binding assay and its subsequent application.
\end{abstract}

Several methods for the measurement of radioligand-receptor binding in vivo using positron emission tomography (PET) have been proposed (Mintun et al., 1984; Farde et al., 1986; Perlmulter et al., 1986; Wong et al., 1986a, b; Logan et al., 1987).

\footnotetext{
Received June 28, 1988; revised Dec. 14, 1988; accepted Jan. 9, 1989.

We wish to thank Ken Larson, Tom Videen, Joanne Markham, and Mark Mintun for invaluable advice and assistance. We also appreciate the expert technical assistance of Lennis Lich, Carla Mathias, Katrina Wade, and the other members of the Division of Radiation Sciences. This work was supported by NIH Grants HS06833, HL13851, AG03991, Teacher Investigator Development Award NS00929 (J.S.P.), and the generous support of the Greater St. Louis Chapter of the American Parkinson's Disease Association.

Correspondence should be addressed to Joel S. Perlmutter, M.D., Division of Radiation Sciences, Mallinckrodt Institute of Radiology, 510 S. Kingshighway, St. Louis, MO 63110.

Present address: Cyclotron/PET Facility, University of Michigan Medical Center, Ann Arbor, MI 48109

Copyright (C) 1989 Society for Neuroscience $0270-6474 / 89 / 072344-09 \$ 02.00 / 0$
}

Different approaches vary in the underlying assumptions, choice of appropriate radioligand, details of implementation, and methods of data analysis. Basically, the different methods can be divided into those that assume equilibrium between the administered radioligand and brain receptors (Farde et al., 1986), those that assume steady state (Wong et al., 1986a, b), and nonsteady-state methods (Mintun et al., 1984; Perlmutter et al., 1986).

In particular, we have developed a non-steady-state technique based upon a 3-compartment model (Mintun et al., 1984) that represents the in vivo behavior of an intravenously injected radioligand (Mintun et al., 1984). The model subsequently has been modified to account for intravascular accumulation of radiolabeled metabolites of the administered radioligand, ${ }^{18} \mathrm{~F}$-spiperone $\left({ }^{18} \mathrm{~F}-\mathrm{SP}\right.$; Perlmutter et al., 1986). Preliminary observations using carrier-added ${ }^{18} \mathrm{~F}$-SP showed a decrement in radioligand-receptor binding in a baboon pretreated with a large dose of unlabeled SP (Perlmutter et al., 1986). The same method, using no-carrier-added ${ }^{18} \mathrm{~F}$-SP containing $<2 \mu \mathrm{g}$ of unlabeled SP, has also been used to demonstrate an increase in radioligand-receptor binding in a patient with untreated parkinsonism due to 1-methyl-4-phenyl-1,2,3,6-tetrahydropyridine (MPTP; Perlmutter et al., 1987). None of these studies, however, validates the non-steady-state technique.

Validation of an in vivo binding assay is a difficult problem. Ideally, one should compare measurements of radioligand-receptor binding using the proposed method with results from a "gold standard." Unfortunately, such a standard does not exist for receptor studies. Although there is a vast accumulation of data using in vitro techniques, these methods depend heavily upon actual assay conditions (Seeman et al., 1984), which clearly differ from the in vivo milieu. The effect of these differences, in part, could account for the differences between in vitro and in vivo binding recently demonstrated for radiolabeled SP in striata of rats after unilateral destruction of the nigrostriatal pathways (Bennett and Wooten, 1986; Perlmutter and Raichle, 1986).

Despite these difficulties, some investigators have found favorable comparisons of estimates of the maximum number of available specific binding sites, $B_{\max }$, using in vivo PET methods with calculations of $B_{\max }$ from in vitro studies (Farde et al., 1986; Wong et al., 1986b). To perform these comparisons, it is necessary to make additional assumptions that must be reviewed cautiously. Such assumptions can affect calculated values of $B_{\max }$ and produce apparent agreement with in vitro values of $B_{\max }$. Therefore, these results, although encouraging, do not constitute full validation.

Another approach to "validation" is to determine the re- 


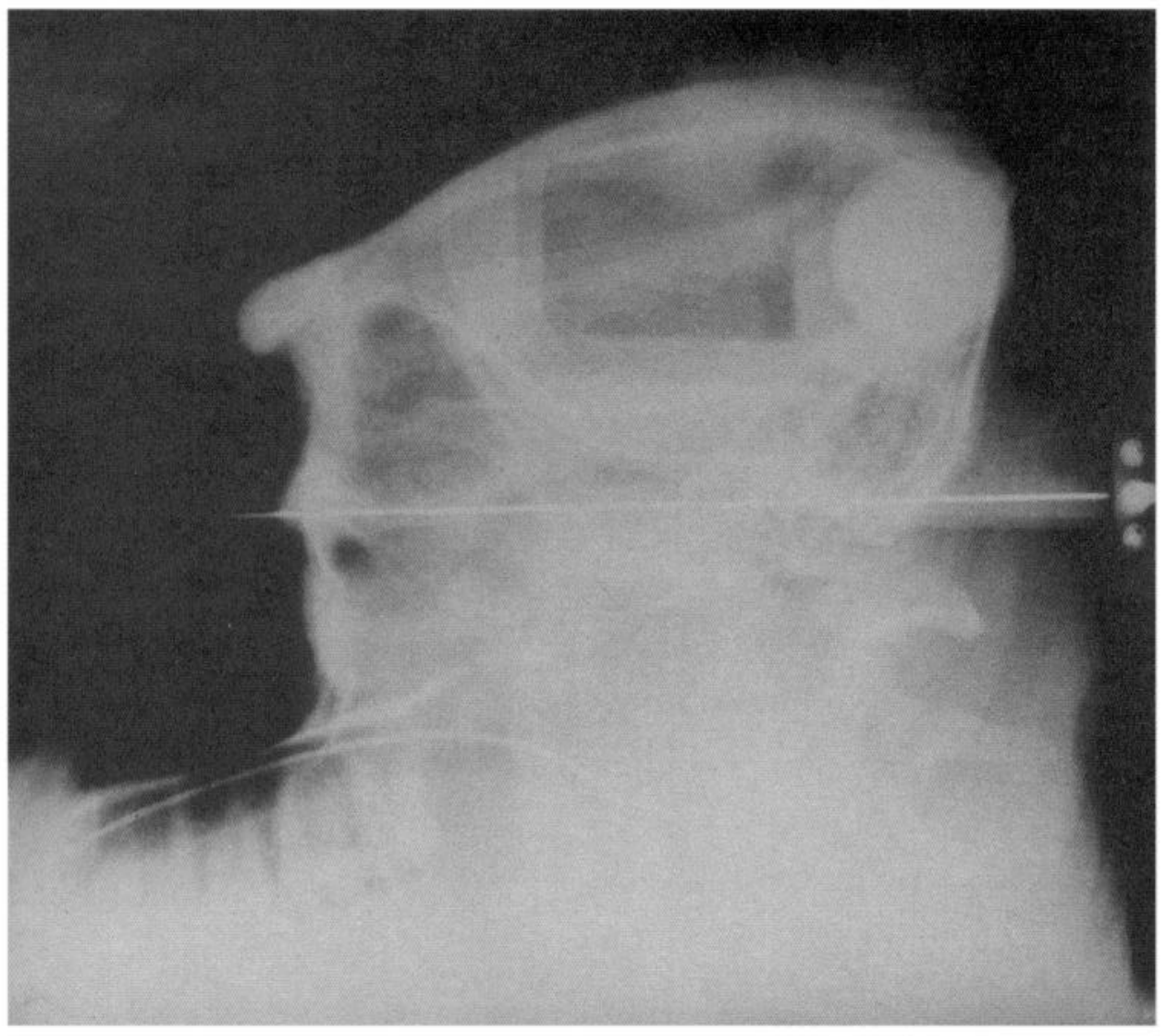

Figure 1. Baboon head holder for PET: This is a lateral skull radiograph of the baboon with the head secured in the modified stereotactic head holder attached to the special PET scanning chair. A laser permanently attached to the wall projects a line across the animal's head that coincides with the position of the lowest of 7 parallel PET slices when the scanning chair is completely advanced into the scanner. A radiopaque wire embedded in leucite is aligned with the line projected by the laser and a lateral skull radiograph is made using a roentgen-ray tube, also permanently fixed to the wall. The radiograph provides a record of the baboon's position within the scanner that permits accurate repositioning for subsequent studies, as well as provides the basis for anatomical localization. Since the magnification of the skull radiograph has been measured, the exact position of all 7 PET slices can be identified on this radiograph and used as described in Materials and Methods for localization.

sponse of the in vivo PET assay to manipulations that cause predictable changes in the availability of specific binding sites. Competition studies can be used for this purpose. For example, an animal can be pretreated with varying doses of unlabeled ligand to compete for the available radioligand-receptor sites prior to each PET experiment. Such a series of experiments should determine if the PET method is sensitive to changes in the apparent number of available receptors. The purpose of this investigation is to apply this approach and determine the sensitivity of the non-steady-state method to alterations in the apparent number of available specific binding sites.

\section{Materials and Methods}

Positron emission tomography. All PET studies were performed with the PETT VI system in the low-resolution mode (Ter-Pogossian et al., 1982; Yamamoto et al., 1982). Data were recorded simultaneously for 7 "slices" with a center-to-center separation of $14.4 \mathrm{~mm}$. In-plane (i.e., transverse) reconstructed resolution was about $16-18 \mathrm{~mm}$ in the center of the field of view and axial resolution was about $14 \mathrm{~mm}$ at the center.

Synthesis of ${ }^{18} F-S P$. No-carrier-added ${ }^{18} \mathrm{~F}$-SP was prepared by a 3-step convergent synthesis that is similar to other published syntheses of radiolabeled butyrophenones (Shiue et al., 1985, 1986). Fluorine-18 fluoride ion was produced by proton irradiation of an oxygen-18-enriched water target (Kilbourn et al., 1985). The aqueous ${ }^{18} \mathrm{~F}$-fluoride was converted to a solution of tetrabutylammonium ${ }^{18} \mathrm{~F}$-fluoride in 100 $\mu$ l dimethylsulfoxide by procedures previously reported (Kilbourn et al., 1984; Brodack et al., 1986).

Two milligrams of 4-nitrophenylcyclopropyl ketone was added to $100-200 \mathrm{mCi}$ of tetrabutylammonium ${ }^{18} \mathrm{~F}$-fluoride and the solution was heated $\left(155^{\circ} \mathrm{C}\right)$ for $25 \mathrm{~min}$. After brief cooling, $1 \mathrm{ml}$ of $1: 1$ methanol: $\mathrm{HCl}(\mathrm{c})$ was added and the solution refluxed for $5 \mathrm{~min}$. The acidic solution was diluted with $10 \mathrm{ml}$ water and passed through a $\mathrm{C}_{18}$ Sep-Pak. The aqueous eluant was discarded, and the product $4^{\prime}$-chloro-4-18 $\mathrm{F}$ - fluorobutyrophenone eluted with $3 \mathrm{ml}$ pentane. The pentane solution

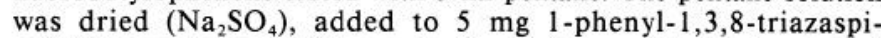
ro[4,5]decan-4-one and $10 \mathrm{mg}$ potassium iodide, and the pentane boiled away. $N$-Methylpyrollidinone, $100 \mu \mathrm{l}$, was added to the residue and the solution heated $\left(155^{\circ} \mathrm{C}\right)$ for $20 \mathrm{~min}$. The dark solution was diluted with $10 \mathrm{ml}$ water and passed through a second $C_{18}$ Sep-Pak. The Sep-Pak was washed with $5 \mathrm{ml}$ water, and the aqueous solutions were discarded. The $\mathrm{C}_{18}$ Sep-Pak then was eluted with $3 \mathrm{ml}$ dichloromethane, and the organic solution dried $\left(\mathrm{Na}_{2} \mathrm{SO}_{4}\right)$.

Purification and isolation of ${ }^{18} \mathrm{~F}$-SP was achieved by HPLC (Whatman Partisil M9 10/50 silica gel column eluted with 97:3:0.05 $\mathrm{CH}_{2} \mathrm{Cl}_{2}$ :methanol: $\mathrm{NH}_{4} \mathrm{OH}$ ). The product was prepared for injection by evaporation of the HPLC solvent and dissolving the residue in $1 \times 10^{-6} \mathrm{M}$ acetic or lactic acid in $0.9 \%$ saline.

Yields of ${ }^{18} \mathrm{~F}$-SP were routinely 6-10\% at end-of-synthesis (synthesis time, $100 \mathrm{~min}$ ). Radiochemical purity determined by TLC (silica gel, 95:5:0.05 $\mathrm{CH}_{2} \mathrm{Cl}_{2}$ :methanol: $\mathrm{NH}_{4} \mathrm{OH}$ ) and HPLC (Spectra-Physics Spherisorb $\mathrm{C}_{18}$ column, $0.9 \times 25 \mathrm{~cm}, 1: 1 \mathrm{CH}_{3} \mathrm{CN}: 0.03 \mathrm{M} \mathrm{KH}_{2} \mathrm{PO}_{4}$ ) was routinely $97-99+\%$. Specific activities determined by HPLC ranged from 1000 to $5000 \mathrm{Ci} / \mathrm{mmol}$ at time of injection. Chemical purity by HPLC showed, in the worst case, a total mass of less than $3 \mu \mathrm{g} \mathrm{SP}$, and $<5 \mu$ g nitro-SP, which has at least 100 -fold lower affinity for SP receptors than SP itself (Pogun et al., 1982), accompanied the ${ }^{18} \mathrm{~F}$-SP preparation.

Experimental procedure. Nine separate PET studies were done on a single male baboon weighing $15 \mathrm{~kg}$. For all studies, the animal was fasted overnight but permitted free access to water up to $2 \mathrm{hr}$ prior to the experiment. For each experiment, the animal was initially anesthetized with ketamine, $10-15 \mathrm{mg} / \mathrm{kg}$, i.m.; given atropine, $0.2 \mathrm{mg}$ i.m., to decrease secretions; paralyzed with gallamine, $2-4 \mathrm{mg} / \mathrm{kg}$ i.v.; intubated with a soft-cuffed endotracheal tube; and ventilated with $70 \%$ nitrous oxide and $30 \%$ oxygen for chemical restraint throughout the length of the study. A 20 -gauge plastic catheter was inserted after local anesthesia with lidocaine $(1 \%)$ into the femoral artery to permit arterial blood sampling, and a similar catheter was placed into an arm vein for the administration of drugs and radiotracers. Blood pressure and pulse were monitored throughout the study with an intra-arterial pressure trans- 


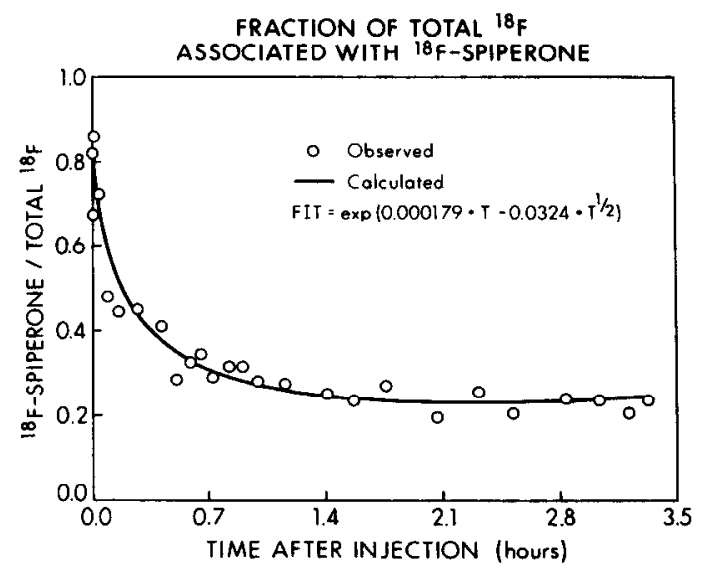

Figure 2. Fraction of total ${ }^{18} \mathrm{~F}$ associated with ${ }^{18} \mathrm{~F}$-spiperone (SP): Fifteen to 26 arterial-blood samples collected after ${ }^{18} \mathrm{~F}-\mathrm{SP}$ administration were analyzed for the accumulation of radiolabeled metabolites. The results for each time point are expressed as the fraction of the total radioactivity in the sample due to ${ }^{18} \mathrm{~F}$-labeled SP. The remaining radioactivity represents ${ }^{18} \mathrm{~F}$-labeled metabolites. The technique for separation of ${ }^{18} \mathrm{~F}-\mathrm{SP}$ and ${ }^{18} \mathrm{~F}$-labeled metabolites is described in Materials and Methods. The results for a typical study are shown here. The circles indicate the observed data, and the solid curve represents a mathematical equation that best fits the data (see Materials and Methods). This equation was then used to calculate the ${ }^{18} \mathrm{~F}-\mathrm{SP}$ content of all the arterialblood samples (up to 50 samples per experiment; see Fig. 5). It is important to note that by $30 \mathrm{~min}$ after ${ }^{18} \mathrm{~F}-\mathrm{SP}$ injection at least $50 \%$ of ${ }^{18} \mathrm{~F}$ radioactivity is bound to labeled metabolites.

ducer. Body temperature was monitored with a rectal probe (Tele-thermometer; Yellow Springs, $\mathrm{OH}$ ) and maintained between 35.5 and $37.5^{\circ} \mathrm{C}$ with a hcating blanket. Frequent arterial-blood gas measurements confirmed that $\mathrm{pCO}_{2}$ and $\mathrm{pO}_{2}$ were constant throughout each procedure.

Unlabeled SP $(15-600 \mu \mathrm{g})$ dissolved in $3-5 \mathrm{ml} \mathrm{0.9 \%} \mathrm{saline} \mathrm{was} \mathrm{injected}$ intravenously over 3-5 min within $30 \mathrm{~min}$ of induction of anesthesia with careful monitoring of blood pressure and pulse.

The head of the baboon was positioned with the aid of a vertical line projected from a laser permanently tixed on the wall. The line coincided with the center of the lowest PET slice when the scanning table was completely advanced into the scanner. The head was firmly clamped in place using a modified stereotaxic head holder with mouth and ear bars. A lateral skull radiograph with the position of the lowest slice marked by a radiopaque wire provided a permanent record of the animal's position within the scanner. Both the modified stereotaxic head holder and the lateral skull radiograph permitted precise repositioning of the animal for repeated studies (Fig. 1). Attenuation characteristics of the head were determined prior to each study by obtaining a transmission scan with a ring source of germanium-68/gallium-68.

For each experiment, regional cerebral blood flow (CBF) was measured using a $40 \mathrm{sec}$ PET scan after the i.v. injection of $20-35 \mathrm{mCi}$ of ${ }^{15} \mathrm{O}$-labeled water (Herscovitch et al., 1983; Raichle et al., 1983). Regional cerebral blood volume (CBV) was determined following the forced inhalation of $50-75 \mathrm{mCi}$ of ${ }^{15} \mathrm{O}$-labeled carbon monoxide and a $5 \mathrm{~min}$ scan (Martin et al., 1987). Measurements of CBF and CBV were done at least $2.5 \mathrm{hr}$ after pretreatment with unlabeled SP that was at least 3 $\mathrm{hr}$ after induction of anesthesia.

At least $3.5 \mathrm{hr}$ after induction of anesthesia, which was about $3 \mathrm{hr}$ after administration of unlabeled SP (if a pretreatment experiment), 3.4-6.5 mCi of no-carrier-added ${ }^{18} \mathrm{~F}$-SP was injected intravenously over $30 \mathrm{sec}$. Sequential PET scans were started immediately with the i.v. injection of radioligand and continued repeatedly for about $3 \mathrm{hr}$. Scan durations were $2 \mathrm{~min}$ initially; longer scans (up to $10 \mathrm{~min}$ ) were required at the end of the study to maintain coincidence counts above $150,000 /$ slice. The midpoint of each scan was recorded as the time elapsed from the start of radioligand injection.

Arterial-blood samples $(0.3 \mathrm{ml})$ were collected every $3-5 \mathrm{sec}$ for the first $60-120 \mathrm{sec}$ after administration of ${ }^{18} \mathrm{~F}-\mathrm{SP}$ and then with decreasing frequency to every 5-10 min during the remainder of the study. These samples were counted in a well counter cross calibrated with PETT VI
(Mintun et al., 1984). The high-frequency sampling at the beginning was necessary to record the blood radioactivity history adequate to define the peak value accurately. Fifteen to 25 arterial-blood samples were also analyzed to measure the percentage of total radioactivity present as ${ }^{18} \mathrm{~F}-\mathrm{SP}$ and as radiolabeled metabolites (Perlmutter et al., 1986; Welch et al., 1988). Each sample was assayed in duplicate. The mean values for each time point were fit empirically to an equation of the form

$$
F=\exp \left(a \cdot t-b \cdot t^{\prime / 2}\right)
$$

where $t$ is time (in sec) after radioligand injection; $F$, fraction of counts due to ${ }^{18} \mathrm{~F}$-SP divided by counts due to total ${ }^{18} \mathrm{~F}$ radioactivity, and $a$ and $b$, arbitrary constants (Fig. 2). This equation and the measurements of total ${ }^{18} \mathrm{~F}$ radioactivity were used to calculate the counts due to ${ }^{18} \mathrm{~F}$ $\mathrm{SP}$ at any given time.

Determination of free fraction of ${ }^{18} \mathrm{~F}-\mathrm{SP}$ in blood. The free fraction of ${ }^{18} \mathrm{~F}-\mathrm{SP}$ in blood $\left(f_{1}\right)$ was determined with the following procedure. About $5 \mathrm{ml}$ of arterial blood were withdrawn in a heparinized syringe. Plasma was separated from a $2 \mathrm{ml}$ aliquot of this blood by centrifugation $(15,000$ $x g$ for $1-2 \mathrm{~min}$ ) and reserved for a later step. ${ }^{18} \mathrm{~F}-\mathrm{SP}$ was added to 1.5 $\mathrm{ml}$ of whole blood, mixed well, centrifuged to separate plasma, and a cellular pellet, and then counted. Aliquots $(200 \mu \mathrm{l})$ of this plasma sample were pipetted into duplicate Centrifree units (\#1), and the Centrifree units centrifuged (about $2000 \mathrm{rpm}$ for $20 \mathrm{~min}, 4^{\circ} \mathrm{C}$ ) in a fixed angle rotor (Sorvall RC2B). The volume of liquid that passed through the filter was accurately measured (in $\mu \mathrm{l}$ ), and the collection vessel and filter unit were separately counted.

Some ${ }^{18} \mathrm{~F}-\mathrm{SP}$ can be trapped with the cellular pellet after separation from whole blood. To determine this amount, this pellet was washed with an equal volume of plasma (from the reserved plasma sample), centrifuged to separate a new cellular pellet and supernatant, and then these 2 samples were counted. Aliquots $(200 \mu 1)$ of this supernatant were applied to duplicate Centrifree units (\#2) and centrifuged as described above.

It was also necessary to determine the amount of nonspecific hinding of free ${ }^{18} \mathrm{~F}$-SP to the Centrifree filter. To accomplish this, ${ }^{18} \mathrm{~F}-\mathrm{SP}$ was added to saline and analyzed with the same Centrifree procedure.

Calculation of the free fraction of ${ }^{18} \mathbf{F}-S P$ in arterial blood $\left(f_{1}\right)$ used the following equation that considers the correction factors described above:

$$
f_{1}=\left(C_{b} V_{a} F_{p} / C_{u} V_{l} S\right)+\left(F_{c} f_{w} C_{d} V_{c} / C_{c} V_{d} S\right)
$$

where $V_{a}$ is the volume of plasma applied to Centrifree $\# 1 ; C_{a},{ }^{18} \mathrm{~F}$ counts applied to Centritree $\# 1 ; V_{b}$, the volume of liquid through Centrifree $\# 1 ; C_{b},{ }^{18} \mathrm{~F}$ counts through Centrifree $\# 1 ; F_{p}$, the fraction of ${ }^{18} \mathrm{~F}$ counts in plasma; $S$, the stick factor (i.e., percentage of ${ }^{18} \mathrm{~F}$ through plasma in control Centrifree); $F_{c}$, the fraction of ${ }^{18} \mathrm{~F}$ in cells; $f_{w}$, the fraction of ${ }^{18} \mathrm{~F}$ washed from cellular pellet; $V_{c}$, the volume of plasma wash applied to Centrifree $\# 2 ; C_{c},{ }^{18} \mathrm{~F}$ counts applied to Centrifree $\# 2$; $V_{d}$, the volume of liquid through Centrifree $\# 2$; and $C_{\dot{d}},{ }^{18} \mathrm{~F}$ counts through Centrifree \#2.

Studies were performed at least 6 weeks apart to permit sufficient time for animal recovery. These studies were approved by the Committee for Humane Care of Laboratory Animals of Washington University School of Medicine.

Regions of interest (ROIs) including midline cerebellum and left and right striata were identified on PET images as follows. The appropriate PET slices containing striata and cerebellum were selected using the lateral skull radiograph obtained at the time of each PET study as described above. The position of the ROIs on appropriate PET slices were identified using proportional measurements of corresponding sections from a stereotaxic atlas of the baboon (Davis and Huffman, 1968). The edges of the baboon brain were defined using a standard threshold routine with the transmission image made from the transmission scan performed as described above (Fox et al., 1985). The outline of the brain made in this fashion is shown in Figure 3. Once the position of the ROIs had been established, an automated regional analysis routine extracted regional measurements from identical positions on all sequential PET images collected after injection of ${ }^{18} \mathrm{~F}-\mathrm{SP}$, as well as from the blood volume and blood flow images (Fig. 3).

Three-compartment model. A 3-compartment model describing the in vivo behavior of ${ }^{18} \mathrm{~F}-\mathrm{SP}$ was used to analyze the data (Perlmutter et al., 1986) and will be described briefly here. The basis of the model assumes the following behavior of ${ }^{18} \mathrm{~F}$-SP. After i.v. injection, ${ }^{18} \mathrm{~F}-\mathrm{SP}$ is distributed within the intravascular space as free tracer and tracer bound 


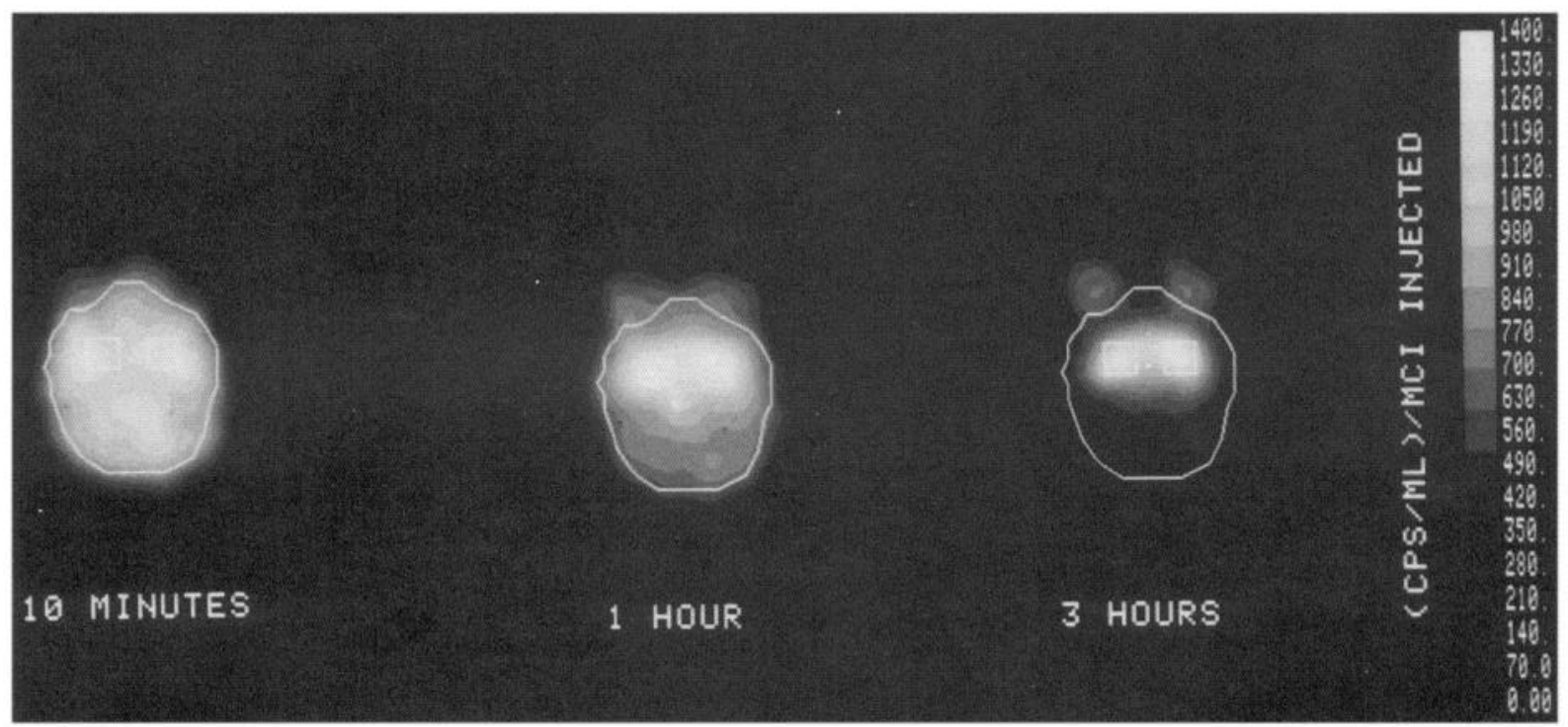

Figure 3. PET images at the level of striatum: Sequential PET images were started immediately after i.v. injection of ${ }^{18} \mathrm{~F}-\mathrm{SP}$. Scan durations were $2 \mathrm{~min}$ initially; longer scans (up to $10 \mathrm{~min}$ ) were required at the end of the study to maintain coincidence counts about $150,000 / \mathrm{slice}$. Three scans from a control study show the distribution of radioactivity at 10 minutes, 1 hour, and 3 hours after injection. Data for these images were collected over $5 \mathrm{~min}$. The scales associated with each image are in units of counts/sec/mCi of ${ }^{18} \mathrm{~F}-\mathrm{SP}$ injected, decay-corrected to the time of radioligand administration. The outlined templates represent the edges of the brain defined from the transmission scan obtained with a ring source of gallium68/germanium-68. This outline is crucial for determination of the locations of regions of interest using proportionate measurements as described in Materials and Methods. Radioactivity preferentially accumulated in striata, as well as in areas anterior to the edge of the brain previously found to correspond to the eyes (Mintun et al., 1984). Note that initially there is a relatively high amount of radioactivity in areas surrounding the striata, whereas at later times, the surrounding regions have relatively low amounts of radioactivity. Therefore, measurements of striatal activity are overestimated at early times and underestimated at later times because of partial volume averaging. Since the distribution of radioactivity continues to change over the $3 \mathrm{hr}$ of the experiment, correction for this factor would be very complex.

to nonspecific sites in plasma. Specific sites also might exist, such as serotonergic sites on platelets but are ignored in this analysis. Unbound ligand is free to cross the blood-brain barrier (BBB) and enter the cerebral extravascular space. Within the extravascular space, ligand can be free, nonspecifically bound or specifically bound to saturable sites (i.e., receptors). This is the basis for the 3-compartment model shown in Figure 4. More precisely, 5 compartments have been described. Since association-dissociation kinetic rate constants for nonspecific binding are assumed to be much larger than the compartmental rate constants, the free and nonspecifically bound moieties on either side of the BBB can be viewed as existing in single compartments. In this manner, the 5 compartments are collapsed to 3 (Mintun et al., 1984; Perlmutter et al., 1986). Each compartment corresponds to a volume in which radioligand can distribute (i.e., the intravascular or extravascular space) or, alternatively, to a biochemical state in which it can exist (i.e., bound to a receptor). In this 3-compartment model, compartment 1 represents the intravascular space; compartment 2 , the free and nonspecifically bound tracer within the cerebral extravascular space; and compartment 3 , the specific binding sites within the brain tissue. Together these 3 compartments comprise all of the radioactivity within the field of view of the PET.

A number of important assumptions of the method should be emphasized (Mintun et al., 1984; Perlmutter et al., 1986). (1) Only unbound ${ }^{18} \mathrm{~F}-\mathrm{SP}$ in the plasma can cross BBB. (2) Transport of unbound ${ }^{18} \mathrm{~F}-\mathrm{SP}$ across the BBB is bidirectional and occurs by passive diffusion. (3) Only free ligand within the extravascular space is available to bind to specific receptors (i.e., nonspecifically bound ligand is not available for specific binding). (4) Free and nonspecifically bound ${ }^{18} \mathrm{~F}-\mathrm{SP}$ in vascular and extravascular spaces are essentially in equilibrium at all times. Thus,

Figure 4. Three-compartment model: the 3-compartment model employed to analyze PET data of radioligand-receptor binding in vivo is shown (figure reproduced with permission from Perlmutter, 1988). Compartment 1 represents the free and nonspecifically bound tracer within the intravascular space; compartment 2 , the free and nonspecifically bound tracer within the cerebral extravascular space; and com-

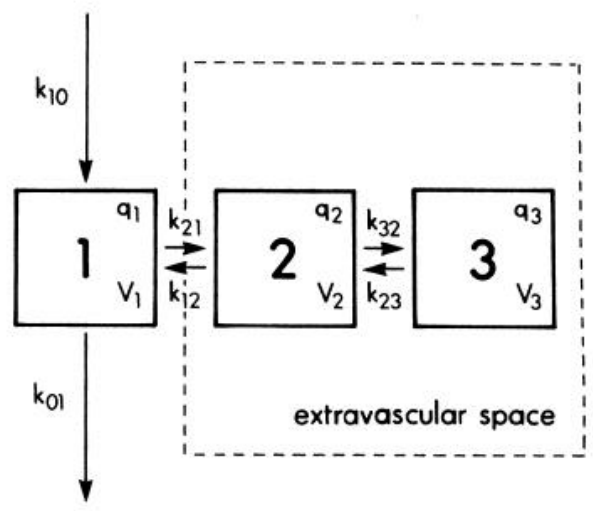

partment 3 , the specific binding sites within the extravascular space. Together these compartments contain all radiotracer within the field of view of the PET. Directions of passage of tracer into and out of the field of view as well as its movements between compartments are indicated by the arrows. Following conventional compartmental analysis notation, the turnover rate constants $k_{u}$ denote fractions of radiotracer in compartments $j$ that move per unit time into compartments $i$. Zero subscript denotes the surroundings external to all compartments and to the PET region of interest. Tracer enters the field of view of the PET via flowing blood. $V_{i}$ is the physical volume of compartments $i$, and $q$ is the quantity of radiotracer within that compartment. The variables estimated with the non-steady-state method include the free fraction in compartment $2\left(f_{2}\right)$, the local permeability-surface-area product $(P S)$ for ${ }^{18} \mathrm{~F}-\mathrm{SP}$, the dissociation rate constant of radioligand-receptor complex $\left(k_{-1}\right)$ and the combined forward rate constant $\left(k_{1}^{\prime}\right)$ that represents the product of the association rate constant and the apparent maximum number of available specific binding sites. In terms of standard compartmental notation, $P S=k_{21} V_{1} / f_{1}\left(f_{1}\right.$ is the free fraction in compartment 1 ); $k_{-1}=k_{23}$; and $k_{1}^{\prime}=k_{32} / f_{2}$ (for a complete description of the mathematical notation and derivation of the relevant equations, see Perlmutter et al., 1986). 


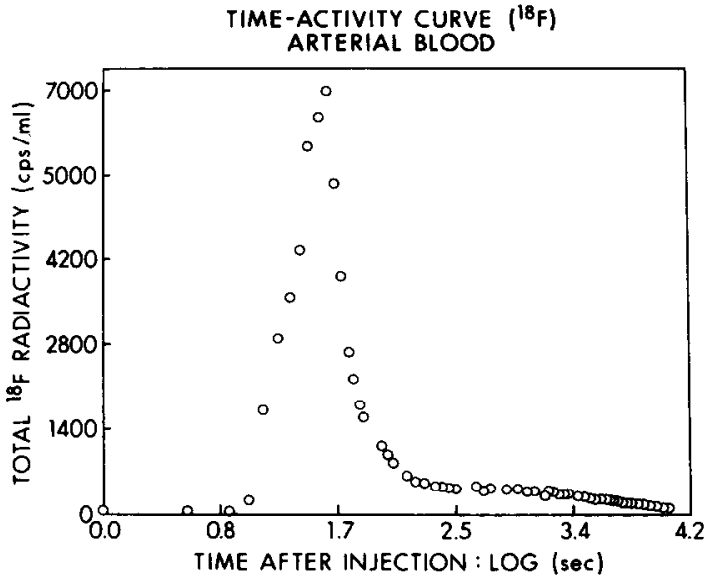

Figure 5. Time-activity curve for ${ }^{18} \mathrm{~F}$ in arterial blood: after injection of ${ }^{18} \mathrm{~F}-\mathrm{SP}$, more than 50 samples of arterial blood were collected for measurements of total ${ }^{18} \mathrm{~F}$ radioactivity. Additionally, the fraction of total radioactivity due to ${ }^{18} \mathrm{~F}$-SP and not to ${ }^{18} \mathrm{~F}$-labeled metabolites was measured on at least 15-26 of these samples. This latter information was used to calculate the amount of arterial-blood radioactivity that represented unmetabolized ${ }^{18} \mathrm{~F}-\mathrm{SP}$ in each of the 50 or more samples.

as free ${ }^{18} \mathrm{~F}-\mathrm{SP}$ crosses the $\mathrm{BBB}$ or binds to specific sites, the relative proportions of free and non-specifically bound ${ }^{18} \mathrm{~F}$-SP remain constant throughout the length of the study. (5) Nonspecific binding is constant throughout different regions of brain and, in particular, is the same in striatum and cerebellum. (6) The physical distribution space of ${ }^{18} \mathrm{~F}-\mathrm{SP}$ is equivalent to the tissue water space. (7) The association of ligand and receptor follows bimolecular association kinetics, and the dissociation of radioligand-receptor complex follows unimolecular kinetics. (8) $\mathrm{Ra}$ dioligand (i.e., ${ }^{18} \mathrm{~F}-\mathrm{SP}$ ) does not occupy a significant fraction of unoccupied receptors during the course of the PET study. (9) Labeled metabolites of the ${ }^{18} \mathrm{~F}-\mathrm{SP}$ do not cross the BBB and are not produced within the brain tissue (i.e., all radioactivity in the extravascular space is associated with ${ }^{18} \mathrm{~F}-\mathrm{SP}$ ). The validity and limitations of these assumptions have been addressed previously (Mintun et al., 1984: Arnett et al., 1985; Perlmutter et al., 1986; Logan et al., 1987).

The model is represented by a set of differential equations (Perlmutter et al., 1986). Several of the variables are either measured directly with PET (e.g., regional radioactivity after injection of ${ }^{18} \mathrm{~F}-\mathrm{SP}$ ), obtained independently (e.g., free fraction of ${ }^{18} \mathrm{~F}-\mathrm{SP}$ in arterial blood and accumulation of radiolabeled metabolites in arterial blood), or assumed. It is assumed that the cerebellum contains no specific hinding sites for ${ }^{18} \mathrm{~F}$-SP (i.e., no third compartment containing receptors), leaving only 2 unknown variables to be estimated: the nonspecific binding fraction in compartment $2\left(f_{2}\right)$ and the local permeability-surface-area product $(P S)$. This value of $f_{2}$ then is assumed to be the same in striatum, reducing the number of unknown parameters there to 4 : (1) the local $P S$, (2) the dissociation rate constant, (3) the association rate constant $k_{a}$, and (4) the maximum number of available specific binding sites, $B_{\max }$. Since the specific activity of ${ }^{18} \mathrm{~F}-\mathrm{SP}$ is very high, the association rate constant $k_{a}$ and $B_{\max }$ cannot be determined independently (Mintun et al., 1984; Perlmutter et al., 1986) and are combined into a single term known as the combined forward-rate constant, defined as the product of $k_{a}$ and $B_{\max }$ (Perlmutter et al., 1986).

Parameter estimation employing a modification of Marquardt's algorithm (Marquardt, 1963) was used to analyze the PET and arterialblood data, as previously described (Perlmutter et al., 1986).

\section{Results}

A typical time-activity curve for total ${ }^{18} \mathrm{~F}$ in arterial blood is shown in Figure 5. There was no appreciable changc in this curve for the different experiments including pretreatment with high doses of unlabeled spiperone. Similarly, there was no consistent change in the rate of accumulation of radiolabeled metabolites in arterial blood. A typical metabolite study is shown in Figure 2.

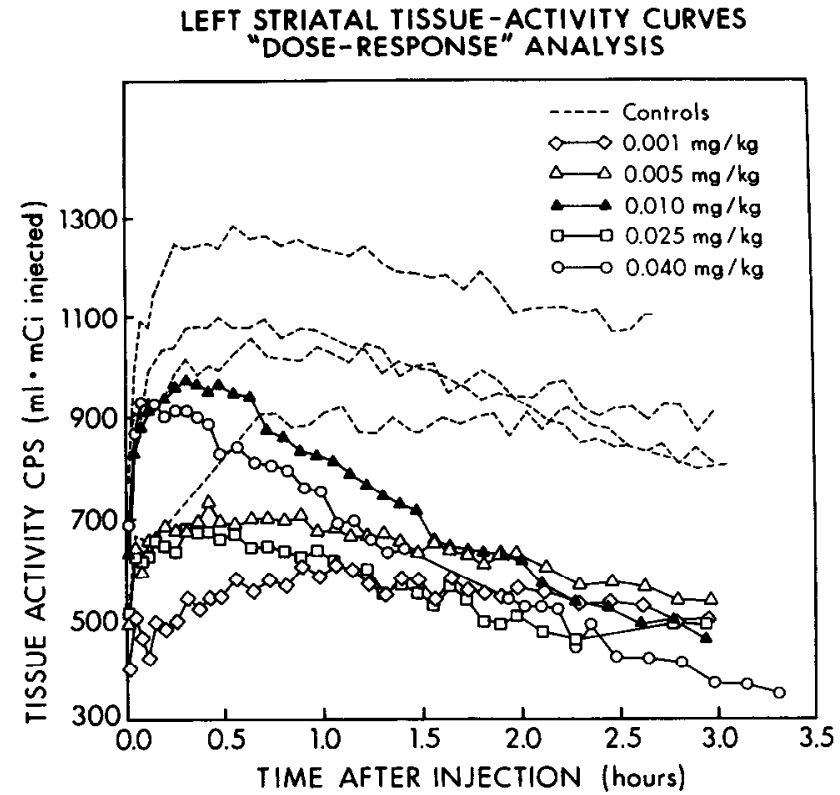

Figure $6 . \quad$ Left striatal tissue-activity curves- "dose-response" analysis: Tissue-activity. curves for left striatum are shown for 9 separate PET studies performed with the same baboon. Unlabeled SP $(0.001-$ $0.040 \mathrm{mg} / \mathrm{kg}$ ) was injected intravenously $3 \mathrm{hr}$ prior to ${ }^{18} \mathrm{~F}-\mathrm{SP}$ in 5 of the studies. Sequential PET scans began immediately after injection of radioligand and continued for $3 \mathrm{hr}$. Radioactivity measurements for the left striatal region for each of the sequential scans were obtained as described in Materials and Methods and then corrected for radioactive decay and normalized to the $\mathrm{mCi}$ of ${ }^{18} \mathrm{~F}$ injected. The rate of decline in striatal radioactivity appears to increase with higher amounts of unlabeled SP. The general shape, but not the height, of the control curves is very similar to the curve corresponding to the study with a pretreatment dose of $0.001 \mathrm{mg} / \mathrm{kg}$. The peaks of the curves do not reflect the pretreatment dose of unlabeled SP or the subsequent calculation of the apparent combined forward rate constant.

The mean $( \pm \mathrm{SD})$ blood flow and blood volume for the cerebellar region was $47(10) \mathrm{ml} /(100 \mathrm{gm} \cdot \mathrm{min})$ and $3.9(0.54) \mathrm{ml} /$ $100 \mathrm{gm}$, respectively. For the striatal regions, blood flow was $52(11) \mathrm{ml} /(100 \mathrm{gm} \cdot \mathrm{min})$ and blood volume was $3.3(0.55) \mathrm{ml} /$ $100 \mathrm{gm}$.

After the injection of ${ }^{18} \mathrm{~F}-\mathrm{SP}$, radioactivity gradually accumulated preferentially in regions containing $S P$ receptor sites (Fig. 3). Radioactivity also accumulated in a region just anterior to the striata on both sides of the brain. The relationship of these anterior regions with the outline of the brain demonstrates that these areas are outside of the brain, and they coincide with the position of the eyes, likely reflecting uptake in the retina (Mintun et al., 1984). Increasing the amount of unlabeled SP given as pretreatment caused an apparent decline in striatal accumulation of radioactivity $3 \mathrm{hr}$ after ${ }^{18} \mathrm{~F}-\mathrm{SP}$ administration as judged solely on the appearance of the PET scans. This apparent decline in tissue radioactivity judged at a single point in time, however, was not entirely consistent. For example, striatal accumulation was slightly higher after pretreatment with 0.025 $\mathrm{mg} / \mathrm{kg}$ unlabeled SP compared with $0.010 \mathrm{mg} / \mathrm{kg}$ (Fig. 6). Such inconsistencics underscore the necd for a quantitative approach to the analysis of such data (see below).

Similarly, the decay-corrected time-activity curves for the left striatum demonstrate the change in the rate of accumulation of striatal activity (Fig. 6). Again, review of the time-activity curves reveals that all the studies preceded by unlabeled SP had lower 
Table 1. "Dose-response" analysis

\begin{tabular}{|c|c|c|c|c|c|}
\hline \multirow[b]{2}{*}{ Study } & \multirow[b]{2}{*}{$\begin{array}{l}\text { Dose } \\
(\mathrm{mg} / \mathrm{kg})\end{array}$} & \multirow[b]{2}{*}{$f_{1}$} & \multirow[b]{2}{*}{$f_{2}$} & \multicolumn{2}{|c|}{$P S\left(\sec ^{-1}\right)$} \\
\hline & & & & $\begin{array}{l}\text { Cere- } \\
\text { bellum }\end{array}$ & Striatum \\
\hline M122 & None & 0.089 & 0.014 & 0.019 & $0.025(0.001)$ \\
\hline M124 & 0.005 & 0.079 & 0.022 & 0.028 & $0.032(0.001)$ \\
\hline M126 & 0.001 & 0.066 & 0.018 & 0.034 & $0.029(0.001)$ \\
\hline M127 & 0.025 & 0.087 & 0.026 & 0.024 & $0.024(0.0001)$ \\
\hline M129 & 0.040 & 0.073 & 0.018 & 0.021 & $0.028(0.0004)$ \\
\hline M132 & 0.010 & 0.080 & 0.024 & 0.022 & $0.027(0.001)$ \\
\hline M136 & None & 0.083 & 0.024 & 0.023 & $0.024(0.001)$ \\
\hline M139 & None & 0.075 & 0.019 & 0.027 & $0.029(0.002)$ \\
\hline M143 & None & 0.109 & 0.030 & 0.023 & $0.029(0.002)$ \\
\hline $\begin{array}{l}\text { Mean } \\
\text { (SD) }\end{array}$ & & $\begin{array}{c}0.082 \\
(0.012)\end{array}$ & $\begin{array}{c}0.022 \\
(0.005)\end{array}$ & $\begin{array}{c}0.025 \\
(0.004)\end{array}$ & $\begin{array}{c}0.028 \\
(0.003)\end{array}$ \\
\hline
\end{tabular}

Nine separate PET studies were performed with the same baboon. Different doses of unlabeled spiperone (SP) (Dose) were injected intravenously prior to 5 of the PET studies; 4 studies served as controls. The intravascular $\left(f_{1}\right)$ and extravascular $\left(f_{2}\right)$ free fraction, as well as regional permcability surfacc-area product $(I S)$ for ${ }^{18} \mathrm{~F}$-SP were obtained for each experiment. Values for striatum represent the mean (SD) of left and right sides. All values are calculated for a $1.0 \mathrm{cc}$ tissue volume.

curves than control studies. The position of each time-activity curve does not seem to reflect the dose of unlabeled SP. For example, the time-activity curve for the study with a pretreatment dose of $0.001 \mathrm{mg} / \mathrm{kg}$ seems lower than most of the other pretreatment studies. Closer inspection, however, suggests that the rate of decline from the peak of the time-activity curve increased as the dose of unlabeled SP increased. The true differences in tracer behavior, however, only become apparent with more quantitative treatment of the data using our 3-compartment, non-steady-state method.

Measurements of the free fraction, $f_{1}$, of ${ }^{18} \mathrm{~F}$-SP in arterial blood did not change consistently throughout the series (Table 1). Similarly, the calculations of the free fraction, $f_{2}$, in the brain tissue (i.e., the reciprocal of the nonspecific binding fraction) and the local $P S$ for ${ }^{18} \mathrm{~F}-\mathrm{SP}$ did not change consistently (Table 1).

The apparent combined forward rate constant (i.e., product of the association rate constant $k_{a}$ and apparent $B_{\max }$ ) declined with increasing dose of unlabeled SP (Fig. 7). The dissociation rate constant $k_{-1}$, however, did not change consistently (Table 2). It should be noted that the estimate of the dissociation rate constant is not made as confidently as the estimate of the combined forward rate constant. This can be described best by indicating the coefficient of variation for individual estimates for each variable for each experiment (Table 2 ). This represents the $\mathrm{SD}$ of the individual estimate divided by the mean estimate for that variable. The mean coefficients of variation for the apparent combined forward rate constant and the dissociation rate constant are listed in Table 2. Note that this is different from the SD of the values for a given variable across experiments (the SD deviation for estimated combined forward rate constants is shown by the error bars in Fig. 7). The latter indicates the variability in arriving at the same value for a given variable, rather than the confidence in estimating that variable in a given experiment.

\section{Discussion}

We have demonstrated that our non-steady-state method for estimating radioligand-receptor binding can detect a decrease

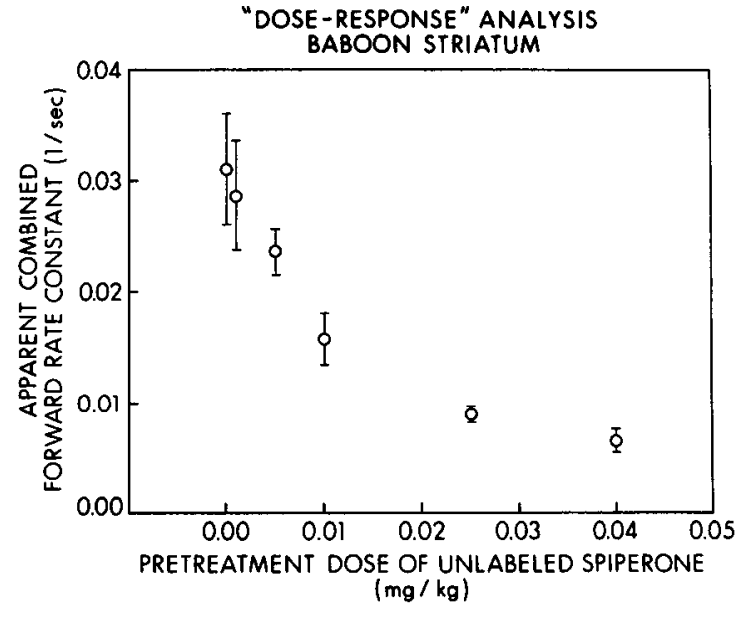

Figure 7. "Dose-response" analysis: Nine separate PET studies were performed with the same baboon. Unlabeled SP $(0.001-0.040 \mathrm{mg} / \mathrm{kg})$ was injected intravenously $3 \mathrm{hr}$ prior to ${ }^{18} \mathrm{~F}$-SP in 5 of the studies; 4 studies served as controls. The apparent combined forward rate constant (equal to the product of the apparent maximum number of specific binding sites and the association rate constant of radioligand for receptor) was calculated for left and right striata. The mean values of leftand right-sided values ( $\pm 1 \mathrm{SD}$, as indicated by the error bars) are shown. There was a consistent decline in the apparent combined forward rate constant as the "dose" of unlabeled SP increased.

in the apparent number of available specific binding sites. This has 2 important implications. First, it is an important component of the validation of this method. Manipulation of the apparent number of available specific binding sites by pretreatment with unlabeled SP produced a predictable decrease in the calculated apparent combined forward rate constant (the number of apparent available specific binding sites times the association rate constant). This type of operational validation is necessary since there is no "gold standard" method for comparison with this type of in vivo binding PET assay. A second implication of these results is that the assay is sensitive to alterations in receptors that are likely to be clinically relevant.

\begin{tabular}{lllllr}
\hline Table 2. & "Dose-response" analysis & & \\
Study & $\begin{array}{l}\text { Dose } \\
(\mathrm{mg} / \mathrm{kg})\end{array}$ & $\begin{array}{l}k^{\prime}{ }_{1} \\
\left(\mathrm{sec}^{-1}\right)\end{array}$ & $\begin{array}{l}C F \\
(\%)\end{array}$ & $\begin{array}{l}k_{-1} \\
\left(\mathrm{sec}^{-1}\right)\end{array}$ & \multicolumn{1}{c}{$\begin{array}{l}C F \\
(\%)\end{array}$} \\
\hline M122 & None & 0.0304 & $(9.7)$ & 0.000196 & $(17.8)$ \\
M124 & 0.005 & 0.0236 & $(4.9)$ & 0.000188 & $(8.4)$ \\
M126 & 0.001 & 0.0286 & $(9.4)$ & 0.000208 & $(16.0)$ \\
M127 & 0.025 & 0.0089 & $(8.2)$ & 0.000109 & $(22.8)$ \\
M129 & 0.040 & 0.0065 & $(6.3)$ & 0.000212 & $(7.2)$ \\
M132 & 0.010 & 0.0156 & $(6.9)$ & 0.000398 & $(8.5)$ \\
M136 & None & 0.0248 & $(5.3)$ & 0.000171 & $(9.1)$ \\
M139 & None & 0.0374 & $(8.4)$ & 0.000346 & $(10.6)$ \\
M143 & None & 0.0320 & $(5.8)$ & 0.000212 & $(8.4)$ \\
Mean & & & 7.2 & & 12.1 \\
(SD) & & & $(2.1)$ & & $(5.6)$
\end{tabular}

Nine separate PET studies were performed with the same baboon. Different doses of unlabeled spiperone (SP) (Dose) were administered prior to the PET studies. The combined forward rate constants $\left(k_{1}^{\prime}\right)$ and dissociation rate constants $\left(k_{-1}\right)$ listed are the mean values for left and right striata for each experiment. Coefficients of variation $(C F)$ for the estimated variables from each experiment are listed to the right of each mean value. All experiments were performed on the same baboon. Values were calculated for a $1.0 \mathrm{cc}$ tissue volume. 
Mattke (1968) demonstrated that intramuscular injection of about $0.1 \mathrm{mg}$ SP was the smallest dose found to produce the most subtle changes in a handwriting task. This is comparable (although not directly analogous because of such differences as i.m. versus i.v. administration, time after administration, etc.) to about the $0.005 \mathrm{mg} / \mathrm{kg}$ dose in this study that caused an appreciable decline in the calculated apparent combined forward rate constant.

There are, however, several methodological issues that should be addressed regarding these results. One could question whether the design of the study actually violated one of the basic assumptions of the method. In particular, does the radioligand occupy a large fraction of the available specific binding sites during the course of the experiment? This question might arise since we pretreated the animal with varying doses of unlabeled SP to occupy, or compete for, a large number of specific binding sites. Superficially, this might seem to violate the above assumption. In fact, the assumption does not concern the number of sites occupied by unlabeled SP, but rather, the fraction of remaining available specific binding sites occupied by ${ }^{18} \mathrm{~F}-\mathrm{SP}$. Given the very high specific activity of ${ }^{18} \mathrm{~F}-\mathrm{SP}$, the percentage of available specific binding sites occupied by ${ }^{18} \mathrm{~F}-\mathrm{SP}$ was probably very low (Perlmutter and Raichle, 1987). This issue of occupation of a significant number of available specific binding sites limits the dose of unlabeled SP that can be used for pretreatment. Much higher doses than used in this series of experiments would limit the apparent number of available specific binding sites and violate one of the assumptions of the model. The exact number of occupied specific binding sites, however, cannot be calculated. (For an estimate of the fraction of occupied sites, see Perlmutter and Raichle, 1987.)

It also should be noted that pretreatment with unlabeled SP $3 \mathrm{hr}$ prior to injection of ${ }^{18} \mathrm{~F}-\mathrm{SP}$ is not sufficient time for equilibrium to occur between receptor sites and unlabeled SP. It has been demonstrated previously that labeled SP continues to accumulate preferentially in striatum for several more hours (Arnett et al., 1985). Therefore, the number of sites occupied by unlabeled SP likely changed throughout the $3 \mathrm{hr}$ of data collection after the injection of ${ }^{18} \mathrm{~F}-\mathrm{SP}$, and the apparent number of available specific binding sites for ${ }^{18} \mathrm{~F}$-SP was not constant during each experiment. This does not negate our conclusions from this study since the purpose was to determine the sensitivity of the non-steady-state method for detecting a decrease in the apparent number of available specific binding sites and not to determine the actual number of sites. Thus, we use the term "apparent number of available specific binding sites" in this context.

This also directly limits further interpretation of our results. It would be incorrect to attempt to calculate $B_{\max }$ from our data for several reasons. First of all, the actual number of sites occupied during each experiment was not truly constant, as described in the previous paragraph. Application of an equilibrium-based saturation analysis, similar to a Scatchard analysis, also would be inaccurate, as the data were not collected under equilibrium conditions. Additionally, measurement of regional radioactivity obtained with $P E T$ can under- or overestimate the true radioactivity content of striatum due to partial volume averaging (Mazziotta et al., 1981). Correction for this factor is a complicated issue that depends not only upon the exact geometry of the region of interest, but also on the distribution of tissuc radioactivity in surrounding arcas. This becomes cven more complex as the distribution of radioactivity changes during the $3 \mathrm{hr}$ of the experiment, as shown in Figure 3. For all these reasons, we choose not to calculate a particular value of $B_{\max }$ from these data.

Another technical point that should be considered in this investigation is the timing of pretreatment with unlabeled SP. As noted above, pretreatment $3 \mathrm{hr}$ prior to injection of ${ }^{18} \mathrm{~F}-\mathrm{SP}$, in part, was to allow sufficient time for unlabeled SP to reach available specific binding sites. It is also clear, however, that equilibrium does not occur between unlabeled SP and these binding sites within $3 \mathrm{hr}$. Additionally, we have found in preliminary studies that i.v. administration of $0.20 \mathrm{mg} / \mathrm{kg}$ unlabeled SP causes a transient increase in regional blood flow of approximately $30 \%$ in striatum lasting for $30-45 \mathrm{~min}$ and gradually returning to baseline after $90 \mathrm{~min}$. Interestingly, cerebellar blood flow was not noted to change (unpublished observations). This makes it important to wait at least 90 min after administration of unlabeled SP before the measurement of regional blood flow with ${ }^{15} \mathrm{O}$-labeled water since our in vivo $\mathrm{PET}$ receptor assay assumes that regional blood flow remains constant from the time of its measurement to the completion of the $3 \mathrm{hr}{ }^{18} \mathrm{~F}$ SP study. As a margin of safety, we waited $2.5 \mathrm{hr}$ after unlabeled $\mathrm{SP}$ for the blood flow measurement and $3 \mathrm{hr}$ for the injection of ${ }^{18} \mathrm{~F}-\mathrm{SP}$. If we had co-injected labeled and unlabeled SP, regional delivery of ${ }^{18} \mathrm{~F}$-SP could have been altered during the course of the $3 \mathrm{hr}$ study.

Several assumptions of the non-steady-state method are supported by our results. We assume that specific binding of ${ }^{18} \mathrm{~F}-\mathrm{SP}$ in arterial blood is negligible. Our finding that the free fraction of ${ }^{18} \mathrm{~F}$-SP did not consistently increase as the dose of unlabeled SP increased supports this contention. If there were an appreciable number of specific binding sites, unlabeled SP would have competed with ${ }^{18} \mathrm{~F}$-SP for these specific binding sites, producing an increase in the free fraction of ${ }^{18} \mathrm{~F}-\mathrm{SP}$. Similarly, the free fraction of ${ }^{18} \mathrm{~F}-\mathrm{SP}$ in the extravascular space did not change consistently in this series of experiments. This supports, but does not prove, the assumption of negligible specific binding in cerebellum. This also demonstrates the reproducibility of this measurement over 2 years in the same subject. The variability in the measurements likely reflects not only variability in the assay, but also could indicate physiological change in the animal. Striatal PS for ${ }^{18} \mathrm{~F}-\mathrm{SP}$ also did not change, suggesting that transport across the BBB of ${ }^{18} \mathrm{~F}-\mathrm{SP}$ is not saturable, at least at the doses of unlabeled SP used in this study.

There are several advantages of the non-steady-state method. First, it permits quantification of in vivo receptor binding that is not clear from the appearance of the PET images. The images through the striatum reveal a modest inconsistency in the decline in striatal accumulation of radioactivity with increasing doses of unlabeled SP (Fig. 6). Apparently, the images, alone, do not indicate the particular nature of the change in radioligand-receptor interaction. Similarly, the time-activity curves for the left striatum show a general trend toward a faster rate of decline from the peak value as the dose of unlabeled SP increases (Fig. 6). These curves by themselves, however, do not demonstrate a consistent or quantitative change. Our non-steadystate method, however, demonstrates a consistent and precise change in the estimate of the apparent combined forward rate constant that reflects the alterations in the apparent available number of specific binding sites.

Furthermore, there is a consistent change in the apparent combined forward rate constant (i.c., the product of $k_{a}$ and $B_{\max }$ ) but not in the dissociation rate constant. The former includes 
the apparent number of available specific binding sites, $B_{\max }$, and one would expect a change in this product, as we have found. The dissociation rate constant, however, does not include $B_{\text {miax }}$. Although the dissociation rate constant could conceivably change as a function of mass of ligand administered (Perry et al., 1980), we could not demonstrate a consistent change in our experiments with our method of analysis. This may be due, in part, to the variability in the estimation of the dissociation rate constant which is best described by its higher coefficient of variation compared with the apparent combined forward rate constant (Table 2). This results from the relatively high association rate constant of ${ }^{18} \mathrm{~F}$-SP for receptor compared with the relatively low dissociation rate constant. Therefore, more association events than dissociation events occur during the length of the experiment. Although the dissociation rate constant is relatively low, Logan et al. (1987) demonstrated that it cannot be assumed to be negligible. This rate constant could be measured more confidently if each scanning session continued longer than $3 \mathrm{hr}$.

Nevertheless, within these constraints, our non-steady-state method does permit the evaluation of both the dissociation and combined forward rate constants. Classic methods for the measurement of in vitro receptor binding yield estimates of the equilibrium binding constant, $K_{d}$, which should be equivalent to the ratio of the dissociation and association rate constants. Similar changes in these 2 rate constants, which may be of pathophysiologic importance, would not be detected by techniques limited to estimation of $K_{d}$, alone. In this regard, we have used our method to measure ${ }^{18} \mathrm{~F}$-SP binding in one of the few untreated, symptomatic patients with parkinsonism induced by MPTP (Perlmutter et al., 1987). The combined forward rate constant and the dissociation rate constants were elevated in the patient compared with 10 normals, whereas nonspecific binding in blood and brain were normal. If the increases in the association and dissociation rate constants were similar, then we would predict no change in $K_{d}$ if tissue from this patient had been available for classic in vitro receptor binding analysis. These results also demonstrate that our PET assay is sensitive to an elevation of the combined forward rate constant.

The latter case highlights another advantage of our technique or any dynamic method willing to forego estimation of $B_{\max }$ ilself (Perlmulter el al., 1986; Wong et al., 1986a). This method, as opposed to some others, does not require administration of a large dose of unlabeled dopaminergic antagonist (Farde et al., 1986; Wong et al., 1986b). Patients with parkinsonism could suffer temporary exacerbations of clinical symptoms from unlabeled antagonists because of the relatively increased deficiency of dopamine (Perlmutter, 1988). On the other hand, patients suffering from diseases thought to have relatively excessive dopaminergic function, such as schizophrenics, would less likely be so affected. Nevertheless, $B_{\max }$ cannot be independently estimated without administration of an unlabeled antagonist in amounts likely to produce appreciable side effects. Only the product of $B_{\max }$ and the association rate constant can be estimated. Although this may appear to be an important compromise in our ability to study receptor pharmacology with PET, it has not proven to be so in practice, as exemplified by the patient with MPTP-induced parkinsonism (Perlmutter et al., 1987).

It is equally important to understand the limitations of the non-steady-state method using ${ }^{18} \mathrm{~F}$-SP as the radioligand. Some of these limitations are due to the choice of radioligand. SP and its labeled derivatives specifically bind predominantly to $D_{2}$ dopaminergic and $\mathrm{S}_{2}$ serotonergic sites (List and Seeman, 1981; Palacios et al., 1981; Altar et al., 1985). These different receptor sites are, to a degree, anatomically separate. $\mathrm{D}_{2}$ predominate in striatum and $\mathrm{S}_{2}$ sites predominate in frontal cortex (List and Seeman, 1981; Palacios et al., 1981; Altar et al., 1985; Farde et al., 1985; Lyon et al., 1986), although the relative distribution of receptor types potentially could change under pathologic conditions. Thus, a radioligand with greater specificity would limit this potential source of ambiguity. For example, "C-raclopride has greater specificity for $\mathrm{D}_{2}$ dopaminergic sites with much lower affinity for serotonergic receptors (Farde et al., 1985). In addition to the specificity limitation of SP, its radiochemical synthesis is complicated (Kilbourn et al., 1984; Welch et al., 1988), making it difficult to use routinely. From a practical point of view, a major disadvantage of using the non-steady-state method with ${ }^{18} \mathrm{~F}-\mathrm{SP}$ is the length of time required for the study, at least 2-3 hr after radioligand injection (Mintun et al., 1984; Perlmutter et al., 1986; Logan et al., 1987). A ligand with faster kinetics (i.e., rapid association and reversibility), such as raclopride, would permit a much shorter study (Farde et al., 1985, 1986). Perhaps, the ideal method would employ the non-steady-state method of data analysis and a more suitable radioligand such as radiolabeled raclopride.

In conclusion; we have presented evidence that the non-steadystate method using PET and ${ }^{18} \mathrm{~F}$-SP is sensitive to a decrease in the apparent number of available specific binding sites. This type of operational validation of in vivo receptor binding methods is important since no "gold standard" exists for direct comparisons.

\section{References}

Altar, C. A., H. Kim, and J. F. Marshall (1985) Computer imaging and analysis of dopamine $\left(\mathrm{D}_{2}\right)$ and serotonin $\left(\mathrm{S}_{2}\right)$ binding sites in rat basal ganglia or neocortex labeled by $\left[{ }^{3} \mathrm{H}\right]$ spiroperidol. J. Pharmacol. Exp. Ther. 233: 527-538.

Arnett, C. D., C.-Y. Shiue, A. P. Wolf, J. S. Fowler, J. Logan, and M. Watanabe (1985) Comparison of three ${ }^{18} \mathrm{~F}$-labeled butyrophenone neuroleptic drugs in the baboon using positron emission tomography. J. Neurochem. 44: 835-844.

Bennett, J. P., Jr., and G. F. Wooten (1986) Dopamine denervation does not alter in vivo ${ }^{3} \mathrm{H}$-spiperone binding in rat striatum: Implications for external imaging of dopamine receptors in Parkinson's disease. Ann. Neurol. 19: 378-383.

Brodack, J. W., M. R. Kilbourn, M. J. Welch, and J. A. Katzenellenbogen (1986) The effect of reaction vessel on fluorine-18 resolubilization product yield, and effective specific activity. Int. J. Appl. Radiat. Isot. 37: 217-221

Davis, R., and R. D. Huffman (1968) A Stereotoxic Atlas of the Brain of the Baboon. University of Texas Press, Austin, Texas.

Farde, L., E. Ehrin, L. Eriksson, T. Greitz, H. Hall, C.-G. Hedström, J.E. Litton, and G. Sedvall (1985) Substituted benzamides as ligands for visualization of dopamine receptor binding in the human brain by positron emission tomography. Proc. Natl. Acad. Sci. USA 82 . 3863-3867.

Farde, L., H. Hall, E. Ehrin, and G. Sedvall (1986) Quantitative analysis of $\mathrm{D}_{2}$ dopamine receptor binding in the living human brain by PET. Science 231: 258-261.

Fox, P. T., J. S. Perlmutter, and M. E. Raichle (1985) A stereotactic method of anatomical localization for positron cmission tomography. J. Comput. Assist. Tomogr. 9: 141-153.

Herscovitch, P., J. Markham, and M. E. Raichle (1983) Brain blood flow measured with intravenous $\mathrm{H}_{2}{ }^{15} \mathrm{O}$. I. Theory and error analysis. J. Nucl. Med. 24: 782-789.

Kilbourn, M. R., M. J. Welch, C. S. Dence, T. J. Tewson, H. Saji, and M. Maeda (1984) Carrier-added and no-carrier-added synthesis of $\left[{ }^{18} \mathrm{~F}\right]$ spiroperidol and $\left[{ }^{18} \mathrm{~F}\right]$ haloperidol. Int. J. Appl. Radiat. Isot. 35: 591-598.

Kilbourn, M. R., P. A. Jarabek, and M. J. Welch (1985) An improved 
$\left[{ }^{15} \mathrm{O}\right]$ water target for $\left[{ }^{18} \mathrm{~F}\right]$ fluoride production. Int. J. Appl. Radiat Isot. 36: 327-328.

List, S. J., and P. Seeman (1981) Resolution of dopamine and serotonin receptor components of $\left[{ }^{3} \mathrm{H}\right]$ spiperone binding to rat brain regions. Proc. Natl. Acad. Sci. USA 78: 2620-2624.

Logan, J., A. P. Wolf, C.-Y. Shiue, and J. S. Fowler (1987) Kinetic modeling of receptor-ligand binding applied to positron emission tomographic studies with neuroleptic tracers. J. Neurochem. 48: 7383.

Lyon, R. A., M. Titeler, J. J. Frost, P. J. Whitehouse, D. F. Wong, H. N. Wagner, Jr., R. F. Dannals, J. M. Links, and M. J. Kuhar (1986) ${ }^{3} \mathrm{H}-3-\mathrm{N}$-methylspiperone labels $\mathrm{D}_{2}$ dopamine receptors in basal ganglia and $S_{2}$ serotonin receptors in cerebral cortex. J. Neurosci. 6: 2941 2949.

Marquardt, D. W. (1963) An algorithm for least-squares estimation of nonlinear parameters. SIAM 11: 431-441.

Martin, W. R. W., W. J. Powers, and M. E. Raichle (1987) Cerebral blood volume measured with inhaled $\mathrm{C}^{15} \mathrm{O}$ and positron emission tomography. J. Cereb. Blood Flow Metabol. 7: 421-426.

Mattke, D. J. (1968) A pilot investigation in neuroleptic therapy. Dis. Nerv. Syst. 24: 515-524.

Mazziotta, J. C., M. E. Phelps, D. Plummer, and D. E. Kuhl (1981) Quantitation in positron emission computed tomography: V. Physical-anatomical effects. J. Comput. Assist. Tomogr. 5: 734-743.

Mintun, M. A., M. E. Raichle, M. R. Kilbourn, G. F. Wooten, and M. J. Welch (1984) A quantitative model for the in vivo assessment of drug binding sites with positron emission tomography. Ann. Neurol. 15: 217-227.

Palacios, J. M., D. L. Niehoff, and M. J. Kuhar (1981) [ $\left.{ }^{3} \mathrm{H}\right]$ spiperone binding sites in brain: Autoradiographic localization of multiple receptors. Brain Res. 213: 277-289.

Perlmutter, J. S. (1988) New insights into the pathophysiology of Parkinson's disease: The challenge of positron emission tomography. Trends Neurosci. 11: 203-208.

Perlmutter, J. S., and M. E. Raichle (1986) In vitro or in vivo receptor binding: Where does the truth lie? Ann. Neurol. 19: 384-385.

Perlmutter, J. S., and M. E. Raichle (1987) Concerning strategies for in vivo measurement of receptor binding using positron emission tomography. II. J. Cereb. Blood Flow Metabol. 7: 819-820.

Perlmutter, J. S., K. B. Larson, M. E. Raichle, J. Markham, M. A. Mintun, M. R. Kilbourn, and M. J. Welch (1986) Strategies for in vivo measurement of receptor binding using positron emission tomography. J. Cereb. Blood Flow Metabol. 6: 154-169.

Perlmutter, J. S., M. R. Kilbourn, M. E. Raichle, and M. J. Welch (1987) MPTP-induced up-regulation of in vivo dopaminergic radioligand-receptor binding in humans. Neurology 37: 1575-1579.
Perry, D. C., K. B. Mullis, S. Oie, and W. Sadee (1980) Opiate antagonist receptor binding in vivo: Evidence for a ncw rcceptor binding model. Brain Res. 199: 49-61.

Pogun, S., T. Duelfer, E. G. Corley, R. F. Dannals, B. J. Dranbauer, U. Scheffel, J. M. Waud, H. A. O'Brien, M. J. Kuhar, H. D. Burns, and H. N. Wagner (1982) In Nuclear Medicine in Biology, Vol. 4, C. Raynaud, ed., pp. 3606-3609, Pergamon, Oxford, England.

Raichle, M. E., W. R. W. Martin, P. Herscovitch, M. A. Mintun, and J. Markham (1983) Brain blood flow measured with intravenous $\mathrm{H}_{2}{ }^{\text {s }} \mathrm{O}$. II. Implementation and validation. J. Nucl. Med. 24: 790798.

Seeman, P., C. Ulpian, K. A. Wreggett, and J. W. Wells (1984) Dopamine receptor parameters detected by $\left[{ }^{3} \mathrm{H}\right]$ spiperone depend on tissue concentration: Analysis and examples. J. Neurochem. 43: 221235.

Shiue, C.-Y., J. S. Fowler, A. P. Wolf, M. Watanabe, and C. D. Arnett (1985) Synthesis and specific activity determinations of no-carrieradded (NCA) ${ }^{18} \mathrm{~F}$-labeled butyrophenone neuroleptics-benperidol, haloperidol, spiroperidol, and pipamperone. J. Nucl. Med. 26: 181186.

Shiue, C.-Y., J. S. Fowler, A. P. Wolf, D. W. McPherson, C. D. Arnett, and L. Zecca (1986) No-carrier-added fluorine-18-labeled N-methylspiroperidol: Synthesis and biodistribution in mice. J. Nucl. Med. 27: 226-234.

Ter-Pogossian, M. M., D. C. Ficke, J. T. Hood, M. Yamamoto, and N. A. Mullani (1982) PETT VI: A positron emission tomograph utilizing cesium fluoride scintillation detectors. J. Comput. Assist. T0mogr. 6: 125-133.

Welch, M. J., J. A. Katzenellenbogen, C. J. Mathias, J. W. Brodack, K. E. Carlson, D. Y. Chi, C. S. Dence, M. R. Kilbourn, J. S. Perlmutter, M. E. Raichle, and M. M. Ter-Pogossian (1988) N-(3$\left[{ }^{18} \mathrm{~F}\right]$ Fluoropropyl)-spiperone: The preferred ${ }^{18} \mathrm{~F}$ labeled spiperone analog for positron emission tomographic studies of the dopamine receptor. Nucl. Med. Biol. 15: 83-97.

Wong, D. F., A. Gjedde, and H. N. Wagner, Jr. (1986a) Quantification of neuroreceptors in the living human brain. I. Irreversible binding of ligands. J. Cereb. Blood Flow Metabol. 6: 137-146.

Wong, D. F., A. Gjedde, H. N. Wagner, Jr., R. F. Dannals, K. H. Douglass, J. M. Links, and M. J. Kuhar (1986b) Quantification of neuroreceptors in the living human brain. II. Inhibition studies of receptor density and affinity. J. Cereb. Blood Flow Metabol. 6: 147153.

Yamamoto, M., D. C. Ficke, and M. M. Ter-Pogossian (1982) Performance study of PETT VI, a positron emission tomograph with 288 cesium fluoride detectors. IEEE Trans. Nucl. Sci. 29: 529-533. 